\title{
Restrictive vs. Nonrestrictive Modification and Evaluative Predicates
}

\author{
Fabienne Martin ${ }^{\mathrm{a}}$ \\ ${ }^{a}$ University of Stuttgart, Institute of Linguistics, Keplerstrasse 17, 70174 Stuttgart
}

\section{Introduction}

\subsection{The nonrestrictive bias of evaluative modifiers}

This paper is devoted to a particular aspect of the interpretation of evaluative adjectives (marvelous, horrible), that is, adjectives that are compatible with subjective attitude verbs like find in the construction find $x$ adj (e.g. find marvelous) and give rise to the so-called 'faultless disagreement' pattern. ${ }^{1}$ Evaluative adjectives have often been claimed to manifest a strong, and even exclusive, preference for the nonrestrictive reading (henceforth the 'nonrestrictive bias hypothesis'). For French for instance, Milner (1978:301) claims that adjectives that he calls 'affectifs' (abominable 'awful', horrible 'horrible') cannot be used in a restrictive way. For Spanish, Demonte (2008:71) argues that what she calls 'extreme degree adjectives' (horrible 'horrible', necio 'stupid', espantoso 'awful') and 'qualitative superlative adjectives' (maravilloso 'wonderful', magnífico 'magnificent') are predicative nonrestrictive modifiers. For Catalan, Castroviejo and Schwager (2008:184) assume that adjectives like beautiful are often understood as nonrestrictive. For German, Umbach (2012b) claims that evaluative predicates often cannot be used restrictively. The claim has also been extended to adverbials derived from these adjectives. For instance, Castroviejo (2008:63) argues that her extremely adverbials are nonrestrictive modifiers.

For Romance languages, where both the post- and pre-head positions can regularly be used for a subset of their adjectives, a frequent observation reported

\footnotetext{
${ }^{1}$ If A claims that the dessert is delicious, and B reacts by claiming that it is not, there is a sense in which both A and B are right, i.e. that their disagreement is 'faultless', cf. e.g. Lasersohn (2005), Stephenson (2007).

Evaluative predicates are not the only ones that display faultless disagreement effects; vague scalar predicates (rich, heavy, tall) also do, cf. Richard (2004). However, as Kennedy (t.a.:6) observes, the latter are not systematically acceptable under find.
} 
in support of the 'nonrestrictive bias hypothesis' is that evaluative adjectives are often odd in post-nominal position, cf. e.g. (1) for French. ${ }^{2}$

a. J'ai vu l'affreux voisin ce matin.

I have seen the horrible neighbour this morning

'I saw the horrible neighbour this morning.'

b. \#J'ai vu le voisin affreux ce matin.

I have seen the neighbour horrible this morning

'I saw the horrible neighbour this morning.'

The argument relies on what has been called the complementarity hypothesis, presented and discussed in more details in Section 1.2 below, namely the hypothesis that pre-head modifiers receive a nonrestrictive interpretation in Romance, while post-head modifiers receive a restrictive interpretation, see e.g. Alexiadou (2001); cf. also Wilmet (1980) for French, Vincent (1988) of Italian, Harris (1995) and Demonte (2005) for Spanish, Marchis and Alexiadou (2009) for Romanian. The idea is therefore that (1b) is odd because (i) the adjective being post-nominal, it must have the restrictive reading and (ii) affreux being evaluative, it does not easily get the restrictive reading.

An immediate problem for this argument is that evaluatives $d o$ appear in postnominal positions in corpora, even in the presence of a definite, a factor that had been argued to favour the anteposition by Forsgren (1978). A search in the literary database Frantext for any evaluative modifier studied here delivers many occurrences of the adjective in post-head position. ${ }^{3}$

One of the goals of this paper is to reconcile these data with the nonrestrictive bias and the complementarity hypothesis. The idea pursued is that a modifier can either be (non)restrictive according to the standard definitions, which are purely extensional, or be (non)restrictive with respect to a particular modal base $\alpha$ (thus, $\alpha$-restrictive vs. $\alpha$-nonrestrictive). Being restrictive or $\alpha$-restrictive (respectively nonrestrictive or $\alpha$-nonrestrictive) allows the modifier to appear in the post-head (respectively pre-head) position. In Section 2.1, we recall the standard (purely extensional) definitions of (non)restrictivity. We then show that these definitions cannot distinguish between restrictive and nonrestrictive modifiers in a number of contexts, e.g. in non-partitive indefinites. In Section 2.3, we introduce modal

\footnotetext{
${ }^{2}$ As we will see in Section 3, the problem of (1b) vanishes once the definite determiner is replaced by an indefinite article, something that one has to explain too.

${ }^{3}$ The quantitative corpus study on French newspapers of Thuilier (2012) also confirms that evaluative modifiers appear in both positions. For a total of 525 occurrences of evaluative adjectives (out of 59 different lemmas) in her corpus, 360 (68.6\%) are anteposed and $165(31.4 \%)$ are postposed.
} 
definitions of (non)restrictivity that solve the problem. Section 3 identifies the contexts in which evaluative adjectives can appear in post-nominal position and explains why, on the basis of the definitions of $(\alpha)$-(non)restrictivity built in previous sections. The analysis proposed is compared with two previous accounts of the nonrestrictive bias of evaluative predicates.

The other properties by which pre- and post-head modifiers are traditionally distinguished (like the differences between idiomatic and literal readings, intersective and non-intersective readings, and 'central property modification' versus 'referent modification') are not addressed in this paper. That is, the discussion is restricted to cases where the reading(s) of the adjective remain(s) stable in preand post-nominal position. ${ }^{4}$

\subsection{The scope of the complementarity hypothesis}

The position of the adjective in the DP is known to be relatively free in Romance languages. For French, a recent computational study based on large corpora has shown that the syntactic flexibility of adjectives is often underestimated in theoretical studies (Thuilier 2012): adjectives or adjectival readings supposed to appear in one position only are in fact often attested in the unexpected position in real corpora. $^{5}$

Although almost any adjective in French can be used in the two positions, the degree of syntactic flexibility of the adjective nevertheless varies with its semantic class (among other factors). ${ }^{6}$ For French, Italian and Spanish, color/shape adjectives and nationality adjectives strongly prefer the postnominal position; I will call

\footnotetext{
${ }^{4}$ So for instance, I will ignore cases where the evaluative adjective is non-intersective only in prenominal position and intersective or non-intersective in the postnominal one (cf. Cinque 2003's contrasts between un buon attacante 'a forward good at playing forward' and un attaccante buono 'a forward good at playing forward/ a good-hearted forward'). I will also ignore the 'objective' (non-evaluative) reading evaluative adjectives can have in postnominal position only (cf. e.g. un roman fantastique 'a fantastic novel/a fantasy novel' vs. un fantastique roman 'a fantastic novel'). As for adverbials, I only take their manner reading into account, since it is the only one which can easily appear in pre- and post-verbal position (what is called the agent-oriented reading is generally restricted to pre-verbal positions in French, cf. e.g. Molinier and Lévrier 2000:108-109; cf. also Geuder 2000 for discussion about English adverbials).

${ }^{5}$ For instance, while non-predicative adjectives like supposé 'alleged' are said to be systematically prenominal, the postnominal position is also attested (Thuilier ibid.: 115); inversely, while certain adjectival participles like interdit 'forbidden' or atténuant 'alleviating' have been claimed to be necessarily postponed (Abeillé and Godard 1999), they can be found before the noun in the right context (Thuilier ibid::113).

${ }^{6}$ This is a fact that I take for granted and do not try to explain here. About the correlation between semantic classes and syntactic positions of French adjectives, see e.g. Bouchard (1998).

Apart from the semantic class of the adjective, the other factors having an influence on the position of the adjective are (a) the length of the adjective (short items tend to appear before long ones), (b) its frequency (frequent adjectives tend to be anteposed and less frequent ones tend to
} 
them 'right-adjectives'. On the other hand, monosyllabic evaluative adjectives like bon 'good' or simple non-subsective adjectives like futur 'future' show a strong preference for prenominal position. These will be called 'left-adjectives'. As for non-monosyllabic evaluative adjectives, they are among the classes of adjectives that equally accept both positions (Thuillier 2012). I will call these adjectives 'neutral adjectives'.

The tenants of the complementarity hypothesis do not always make clear whether the hypothesis is supposed to hold for all adjectives or only a subset of them. ${ }^{7}$ Generally, it is illustrated with neutral adjectives. I claim that it holds for neutral adjectives only; for left- and right-adjectives, the preferred position of the adjective allows both the restrictive and the nonrestrictive readings (see below).

The following examples taken from the literature illustrate the complementarity hypothesis for neutral adjectives in different Romance languages; the examples in (a) only have the restrictive (' $R$ ') reading, while the examples in (b) only have the nonrestrictive ('NR') one. The contrast in (2) is due to Demonte (2008) and the one in (3) to Marchis and Alexiadou (2009).

a. Encontré las llaves viejas. (Spanish)

find-PAST-1SG the keys old

$R$ :'I found the subset of keys which are old.'

\# NR: 'I found all members of the set of keys and they are old.'

b. Encontré las viejas llaves.

find-PAST-1SG the old keys

\# $R$ :'I found the subset of keys which are old.'

$N R$ : 'I found all members of the set of keys and they are old.'

a. Legile importante n-au fost votate. (Romanian) laws-the important neg-have been passed

$R$ :'The subset of laws which were important were not passed.'

be postponed, cf. Wilmet 1980), (iii) its morphology (morphologically complex adjectives tend to prefer the post-nominal position, although some morphemes like the negative morpheme in- vote for anteposition, cf. Thuilier 2012) and (iv) syntactic (among other facts, non-degree adverbials massively promote the post-nominal position; the modification by degree adverbials makes the anteposition easier for what I call below 'right-adjectives' and the postposition easier for 'leftadjectives', cf. Thuilier 2012:119).

${ }^{7}$ The complementarity hypothesis is not endorsed by everyone. For instance, Cinque (2010) argues that post-nominal adjectives in Italian are systematically ambiguous between restrictive and nonrestrictive modification, while pre-nominal ones are unambiguously nonrestrictive (see Cinque 2010:114 for references to authors arguing for the same point in other Romance languages). For French, I agree with Cinque for what I call right-adjectives (see below), but I am on the side of the complementarity hypothesis defenders for neutral adjectives. 
\# NR: 'The laws were not passed and they are important.'

b. Importantele legi n-au fost votate. important-the laws neg-have been passed

\# $R$ :'The subset of laws which were important were not passed.'

$N R$ : 'The laws were not passed and they are important.'

a. La police a relâché les étudiants innocents. (French) the police has released the students innocent

$R$ : 'The police released the subset of students which are innocent.' \# NR: 'The police released all the students and they are innocent.'

b. La police a relâché les innocents étudiants. the police has released the innocent students \# $R$ : 'The police released the subset of students which are innocent.' $N R$ : 'The police released all the students and they are innocent.'

An argument for this difference in the interpretation of the adjective is that referring to the complementary set (to the other keys, laws, students) in the context in the following discourse is natural only when the modifier receives the restrictive reading. So for instance, (4a) could be followed unproblematically by the sentence Les autres sont toujours retenus au commissariat 'The others are still detailed at the police station', while this is not so easy in (4b). ${ }^{8}$

The situation is different for adjectives that do not easily move ('non-neutral' adjectives). Right-adjectives like color adjectives can have both the restrictive and nonrestrictive interpretation in the postnominal position, cf. (5a). However, in the marked prenominal position, they only have the nonrestrictive interpretation, cf. (5b).

a. J'aime beaucoup les étagères blanches chez Marie. (French) I like a lot the shelves white at Marie

$R$ : 'I like the subset of shelves at Mary's place which are white.'

$N R$ : 'I like the shelves at Mary's place and they are white.'

b. Trouvez les vertes collines de Strangleronce. (French, Internet) find the green hills of Strangleronce

\#R: 'Find the hills of Strangleronce which are green.'

$N R$ : 'Find the subset of hills of Strangleronce and they are green.'

\footnotetext{
${ }^{8}$ As I will show in section 2.3 through the example (24a), when the definite determiner is replaced with a demonstrative, the problem vanishes: it becomes possible to refer to the complementary set in the following discourse and to assert that the members of the complementary set do not satisfy the modifier even when the modifier is in pre-nominal position.
} 
Inversely, left-adjectives can have both a restrictive and a nonrestrictive reading in their natural prenominal position, cf. (6a), but only get a restrictive reading in the marked postnominal position, cf. (6b). The distribution of readings for each subclass of adjectives is summarised in Table 1 ('A' stands for adjective, ' $\mathrm{N}$ ' for noun) ${ }^{9}$

a. En français, je n'ai lu que les très bons romans In French, I NEG have read only the very good novels de Boris Vian. (French)

of Boris Vian

$R:$ 'In French, I only read the subset of Boris Vian's novels which are very good.'

$N R$ : 'In French, I only read Boris Vian's novels and they are very good.'

b. En français, je n'ai lu que les romans très bons

In French I NEG have read only the novels very good

de Boris Vian.

of Boris Vian

$R$ :'In French, I only read the subset of Boris Vian's novels which are very good.'

\#NR: 'In French, I only read Boris Vian's novels and they are very good.'

Assuming that the complementarity hypothesis holds for neutral adjectives only seems more attractive to me. Indeed, if it held for all of them, this would mean that right- and left-adjectives would systematically have a lexical bias for the restrictive or the nonrestrictive interpretation. This claim is in fact endorsed by some

\footnotetext{
${ }^{9}$ Note that if left-adjectives or right-adjectives receive contrastive Focus, the nonrestrictive reading disappears in their 'unmarked' position, as the following examples show.

a. J'aime bien les étagères BLANCHES chez Marie.

(cp. (5a))

I like well the shelves white at Marie

$R$ : 'I like the subset of shelves at Mary's place which are white.'

\# NR: 'I like the shelves at Mary's place and they are white.'

b. En français, je n'ai lu que les TRÈS BONS romans de Boris Vian.

In French, I NEG have read only the very good novels of Boris Vian

$R$ : 'In French, I only read the subset of Boris Vian's novels which are very good.'

\#NR: 'In French, I only read Boris Vian's novels and they are very good.'

So contrastive Focus triggers the restrictive interpretation. However, a non-focused modifier can receive both interpretations (on the interaction between restrictivity and focus, see e.g. Umbach 2006). 


\begin{tabular}{|l|l|l|}
\hline & AN & NA \\
\hline \hline neutral adjectives & NR & R \\
\hline Left-adjectives & NR \& R & R \\
\hline Right-adjectives & NR & R \& NR \\
\hline
\end{tabular}

Table 1: Subkind of adjectives wrt. the complementarity hypothesis

authors; for instance, Vincent (1988) justifies the fact that nationality adjectives are right-adjectives because 'they are normally contrastive'. But the existence of a lexical bias for non-neutral adjectives is not supported by what we know from experimental studies on the interpretation adjectives receive by default. Firstly, Sedivy et al. (1999) and Sedivy (2003) show that when hearers have to choose between restrictive and nonrestrictive uses of scalar adjectives like tall, of which many are left-adjectives in French (cf. grand 'tall', petit 'small'), ${ }^{10}$ they systematically prefer the restrictive interpretation. If the complementarity hypothesis held for these left-adjectives, they should on the contrary prefer the nonrestrictive reading. Secondly, Sedivy and her colleagues show that this 'restrictive bias' does not show up with colour adjectives, which are right-adjectives in French. But again, if the complementarity hypothesis held for these adjectives, we would expect them to show precisely the (unobserved) restrictive bias. ${ }^{11}$

Observe however that the interpretation of all three types of adjectives (neutral, right- or left-ones) in pre- and post-head position is compatible with the following weaker version of the complementarity hypothesis:

(7) Complementarity hypothesis (weak version): in a pre-head position, modifiers in Romance get at least the nonrestrictive reading, while in a

\footnotetext{
${ }^{10}$ For instance, J'habite dans un village petit/grand. 'I live in a small/big village.' are rather odd in French (but would be fine if très 'very' modified the adjective, cf. fn 6.).

Note that Sedivy and colleagues investigate the interpretation of adjectives in context through eyetracking, and not through offline global judgements (so the 'choice' I allude to should not be understood as a conscious decision). Also, note that these studies do not mention 'restrictivity' per se, but rather speak of 'contrastive' interpretation of adjectives. But I assume that what they mean by contrastive interpretation of adjectives is not different from what is called the restrictive interpretation of modifiers in the literature reviewed above.

${ }^{11}$ Sedivy and colleagues suggest that this difference between scalar and colour adjectives is due to the fact that colour adjectives are frequently used in descriptions of objects even if they are the only objects of their type in context. On the contrary, scalar adjectives would be much more systematically used in order to identify a $N$ among other $N$ s.
} 
post-head position, they get at least the restrictive one.

This is the version I will adopt in this paper for Romance languages, which I will mostly exemplify through French. Moreover, I assume that for Romance neutral modifiers, included the adverbial ones, the stronger version of the hypothesis applies:

(8) Complementarity hypothesis (strong version): in a pre-head position, neutral modifiers in Romance get the nonrestrictive reading only, while in a post-head position, they get the restrictive one only.

\section{Defining restrictivity}

\subsection{Restrictivity: set-based definition}

(Non)restrictivity is rarely explicitly defined in works devoted to (non)restrictive modification, but the traditional intuition behind this notion is generally clear: a modifier $\mathrm{M}$ restrictively modifies the head $\mathrm{H}$ when the contextual set of objects denoted by the modified head $\mathrm{MH}$ is properly included in the contextual set of objects denoted by $\mathrm{H}$. On the other hand, $\mathrm{M}$ nonrestrictively modifies $\mathrm{H}$ if the contextual set of objects denoted by $\mathrm{H}$ equals the contextual set of objects denoted by $\mathrm{MH}$. As Cabredo-Hofherr (in prep.) emphasises, restrictive modifiers are under this traditional definition inherently contrastive: they presuppose the existence of entities of which the description given by the modifier is not true. ${ }^{12}$

Piñón (2005) provides formal definitions of restrictive and nonrestrictive modification that capture this conception of (non)restrictivity. I repeat them in (10).

\footnotetext{
${ }^{12}$ This is made very clear by Bach $(1974: 271)$ (apud Cabredo-Hofherr id.) about restrictive relative clauses: 'A restrictive relative clause presupposes the existence of entities of which the description given in the relative clause is not true'.

Note that this inference can be cancelled and is therefore better analysed as a (conversational) implicature than as a presupposition (Katz 2008). For instance, in French, one can continue the example (4a) so that the inference it triggers that some students are not innocent is cancelled, see e.g. (9) below:
}

(9) La police a relâché les étudiants innocents, et donc, en fait, tous les étudiants, (puisqu'ils the police has released the students innocent and thus in fact all the students since they étaient tous innocents). were all innocent 'The police released all innocent students, and thus, in fact, all students (since they were all innocents).'

In this example, et donc, en fait 'and thus, in fact' indicates that the inference is cancelled (thanks to an anonymous reviewer for pointing this out). See Katz (2008) for Italian and Spanish examples where the restrictivity implicature is also cancelled. 
$\mathscr{M}$ is a model which consists of a non empty set $O$ of objects $o$, a non empty set $S$ of possible situations $s$, and an interpretation function $\llbracket . \rrbracket . ~ M$ and $\mathrm{H}$ designate functions from situations and objects to truth values. ${ }^{13}$

a. M nonvacuously restrictively modifies $\mathrm{H}$ in $s$ iff

$$
\llbracket \lambda o\left[\mathrm{M}_{s}(o) \wedge H_{S}(o)\right] \rrbracket \mathscr{M}_{, g} \subset \llbracket H_{S} \rrbracket \mathscr{M}_{, g} \text { and } \llbracket \lambda o\left[\mathrm{M}_{s}(o) \wedge H_{S}(o)\right] \rrbracket \mathscr{M}_{, g} \neq \emptyset
$$

b. M nonvacuously nonrestrictively modifies $\mathrm{H}$ in $s$ iff

$$
\llbracket \lambda o\left[\mathrm{M}_{s}(o) \wedge H_{s}(o)\right] \rrbracket \mathscr{M}_{, g}=\llbracket H_{S} \rrbracket \mathscr{M}_{, g} \text { and } \llbracket \lambda o\left[\mathrm{M}_{s}(o) \wedge H_{s}(o)\right] \rrbracket \mathscr{M}_{, g} \neq \emptyset
$$

The advantage of the definitions in (10) is that they are neutral regarding what the set of objects $O$ is. They may be physical, abstract objects, events, etc. Note that if the denotation of $\mathrm{H}$ in the situation $s$ (i.e. $\mathrm{H}_{s}$ ) is a singleton set, then, according to (10), the modifier cannot non-vacuously restrictively modify $\mathrm{H}_{s}$. As Piñón observes, this captures the old idea that a proper noun can be nonrestrictively but not restrictively modified.

Under the complementarity hypothesis, this definition captures well the difference between the examples (a) and (b) in (2)-(4) presented in the introduction. I claim that in definites (as in the examples of Section 1), postnominal neutral modifiers have to be restrictive at least in this sense, while prenominal ones have to be nonrestrictive at least in this sense. That is, although in principle, as we will see, (non)restrictivity can be defined in another way, restrictivity as defined in (10) compulsorily applies to modifiers in definites.

\subsection{Contrasts not captured yet}

Although certainly useful, this definition of restrictivity cannot suffice to cover all uses made of this notion in the literature. In particular, as shown below, it cannot among others render the contrasts between restrictive and nonrestrictive modification that have been correlated with a post- vs. pre-head position (i) with adverbials (section 2.2.1) and (ii) with indefinite NPs (section 2.2.2).

\subsubsection{Adverbials}

Peterson (1997:231-238) argued that the distinction between the restrictive and nonrestrictive readings of relative clauses and adjectives also applies to adverbs. ${ }^{14}$

\footnotetext{
${ }^{13}$ The last conjunct in (10a) and (10b) ensures that the modification does not result in the empty set (is not vacuous). In (10a), the first conjunct ensures that the modification by $\mathrm{M}$ results in the elimination of at least one entity from $\mathrm{H}$ (i.e. that at least one entity in the denotation of $\mathrm{H}$ in $s$ is not in the denotation of $\mathrm{M}$ in $s$ ). In (10b), the first conjunct ensures that the modification by $\mathrm{M}$ leaves the denotation of $\mathrm{H}$ in $s$ intact (i.e. that all entities in the denotation of $\mathrm{H}$ in $s$ are also in the denotation of $\mathrm{M}$ in $s$ ).

${ }^{14}$ As Göbbel (2007) fn 14 observes, this view can be traced back to Heny (1973), who claims that 'adverbs placed before the verb rather than after the VP may turn out to have a sort of nonrestrictive force, being an interpolation or comment by the speaker'.
} 
One of Peterson's examples (given on pp. $233 \& 283$ ) is repeated in (11).

(11) The Titanic's sinking rapidly caused great loss of life. (Peterson 1997)

a. restrictive: The Titanic's sinking being rapid caused great loss of life.

b. nonrestrictive: The Titanic's sinking, which [by the way] was rapid, caused great loss of life.

Peterson does not directly correlate this ambiguity with the syntactic position of the adverbial, but Morzycki (2008) agrees with Shaer (2000) that in English, the nonrestrictive reading is not available with postverbal manner adverbials. Shaer (2000:284) illustrates Peterson's ambiguity in (12), where the adverb has a canonical adverbial position (which is not the case in (11), where the adverb can easily be replaced by an adjective). The idea is that each continuation selects a different reading of the adverbial. ${ }^{15}$

(12) The prisoner (loudly) proclaimed his innocence (loudly). (Shaer 2000)

a. Continuation on the restrictive reading (licensed in the pre- and postverbal positions): He woke up all the other prisoners.

b. Continuation on the nonrestrictive reading (licensed in the preverbal position only): He really believed that he had been framed.

These examples illustrate a clear common point to the nonrestrictive adverbial modification and the nonrestrictive adjectival modification in definites, namely that in both cases, the modifier conveys extra information, not central, parenthetical, non at-issue, non negotiable. On the other hand, both restrictive adverbial modification and restrictive adjectival modification in definites are central to the point made by the utterance.

Peterson emphasises that the ambiguity 'is not, however, exactly what it was' with adjectives: with adverbials, the restrictive reading does not amount to the reference to a proper subset of events of a salient set (p. 235). Indeed, in each of the situations described in (11)-(12), there is a single event described (a singleton set), independent of the structural position of the adverb. Hence, the modification can only be nonrestrictive according to Piñón's definition. However, we agree

\footnotetext{
${ }^{15}$ According to an anonymous reviewer, the claim according to which the continuation (b) selecting the nonrestrictive reading is not felicitous when the adverbial is in postverbal position is not empirically adequate. I do not aim to discuss how syntactic positions of English adverbials constrain their interpretation (on this point, see also Göbbel 2007). The only point I want to make here is that the set-based definitions of (non)restrictivity do not suffice to capture the difference between the restrictive vs. nonrestrictive readings of adverbials.
} 
with Peterson, Shaer and Morzycki's hypothesis that the ambiguity illustrated in (12) has something to do with the restrictive vs. nonrestrictive ambiguity found with adjectives.

The idea I develop in Section 2.3 is that for adverbials, modality has to be involved in the definition of restrictive vs. nonrestrictive modification. Before developing this view in detail, I turn now my attention to another context where the differences between neutral modifiers in pre- and post-head position cannot easily be captured by the definitions in (10).

\subsubsection{Indefinites}

According to the definition of restrictivity given in (10), restrictive modifiers are those where a least one member of $\mathrm{H}$ in the situation $s$ does not pertain to $\mathrm{M}$ in $s$. In order to check whether this is the case or not, the interpreter must be able to build a representation of the set $\mathrm{HM}_{s}$ independently of the representation of the set $\mathrm{H}_{s}$. When $s$ is a contextual (minimal) situation, this is easy with definite DPs, because these standardly presuppose their domain of quantification. But with indefinites, things are more complicated. Partitive indefinites (as defined e.g. by Enç 1991) notoriously resemble definites because (among others) they also presuppose a contextually restricted set of entities. Take for instance (13). In this sentence, some blond girls describe girls who are included in the set of girls established by the previous utterance.

(13) Several girls entered my room. I knew some blond girls.

With indefinites of this type, we can also build a representation of members of HM (blond girls) in the contextual situation $s$ which is independent of the representation of the set of $\mathrm{H}$ (girls) in $s$ (the set of girls that entered the room). But non-partitive indefinites do not presuppose a quantification domain. It is then not possible to distinguish the set of HM in the minimal situation $s$ from the set of $\mathrm{H}$ in $s$. For instance, uttered out of the blue, the sentence I was working. Several blond girls entered my room describes a set of contextual blond girls undistinguishable from the set of contextual girls.

With non-partitive indefinites, modifiers will thus systematically be nonrestrictive independently of their syntactic position according to (10) if $s$ is a minimal (contextual) situation. Symptomatically, indefinites are often left explicitly aside in works devoted to (non)restrictivity. Katz (2008:16) explicitly says that indefinite DPs are undefined for (non)restrictivity. Demonte (1999:148) claims the same about Spanish. Cabredo-Hofherr (in prep.) also explicitly leaves aside indefinite NPs in her work on the (non)restrictive relative clauses in German.

The difficulty can be overcome if $s$ is not a contextual, but rather the maximal situation (the entire world). Indeed, as shown below, the difference between 
pre- and post-nominal neutral adjectives can then be captured with indefinites, too. The modifier will be defined as maximally nonrestrictive if all members of the set $\mathrm{H}$ in the maximal situation are members of $\mathrm{M}$; we deal then with what Fabricius-Hansen (2009) calls 'conceptual nonrestrictivity', i.e. cases where the modification does not restrict the extension of the noun, that is if $\llbracket \mathrm{MH} \rrbracket=\llbracket \mathrm{H} \rrbracket$ in the maximal situation. The relation of identity can be semantic (unmarried bachelor), prototypical (white snow) or stereotypical (innocent passengers). The modifier will be maximally restrictive if $\llbracket \mathrm{MH} \rrbracket \subset \llbracket \mathrm{H} \rrbracket$ in the maximal situation.

This way, we can capture the ambiguity illustrated in (14): (14a) can be taken to imply that children are by definition innocent (innocent is maximally nonrestrictive), while (14b) suggests that children can in principle be either innocent or not (innocent is maximally restrictive). The same way, (15a) implies that horsemeat is indigestible by definition, which is not the case of (15b).

a. Supposons qu' il y ait d' innocents assume-IMP.-1PL that it PRN be-SUBJ.PRES INDEF innocent enfants dans l'avion. children in the plane 'Let us assume that there are innocent children in the plane.'

b. Supposons qu' il y ait des enfants assume-IMP.-1PL that it PRN be-SUBJ.PRES INDEF children innocents dans l'avion. innocent in the plane 'Let us assume that there are innocent children in the plane.'

(15) a. indigeste viande de cheval (title, Le Monde, 16.02.13) indigestible horsemeat 'indigestible horsemeat'

b. viande de cheval indigeste horsemeat indigestible 'indigestible horsemeat'

But the differences between pre- and postnominal modifiers in indefinites cannot always be accounted for this way. Take for instance the following pair (16); let us assume that the sentence is uttered out of the blue, so that the indefinite is clearly interpreted as non-partitive.

a. Pierre m'a offert d'horribles fleurs. Pierre me-has offered INDEF horrible flowers 'Pierre offered me horrible flowers.' 
b. Pierre m'a offert des fleurs horribles.

Pierre me-has offered INDEF flowers horrible

'Pierre offered me horrible flowers.'

The 'maximally nonrestrictive' interpretation is blocked in (16a), because it enters into conflict with the by-default assumption that flowers are beautiful. So this time, we cannot capture the difference between (16a) and (16b) by saying that horrible is maximally nonrestrictive in (16a), and maximally restrictive in (16b). And if $s$ is a minimal situation, horrible is nonrestrictive in both cases (the set of contextual horrible flowers is undistinguishable from the set of contextual flowers).

Do we have to conclude that in cases like (16), there is no semantic/pragmatic difference between pre- and post-nominal modifiers, or, if there is some, this difference has nothing to do with the ones we previously dealt with? I do not think so; I claim that the contrast in $(16 \mathrm{a} / \mathrm{b})$ can also be captured in terms of restrictive vs. nonrestrictive modification. However, as for adverbials, we need to appeal to modality again, an idea that is developed in the next section.

\subsection{Towards a modal definition of (non)restrictivity}

One way of summarising the previous criticisms would be to say that the standard definitions of restrictive vs. nonrestrictive modification are much too extensional, for they cannot distinguish restrictive modifiers from nonrestrictive modifiers in situations $s$ where

$$
\llbracket \lambda x\left[\mathrm{M}_{s}(x) \wedge \mathrm{H}_{s}(x)\right] \rrbracket=\llbracket \mathrm{H}_{s} \rrbracket
$$

In such situations $s$, any modifier $\mathrm{M}$ is by definition nonrestrictive, hence there is no way to distinguish restrictive modifiers from nonrestrictive modifiers, which is too weak.

Before proposing a modal definition of restrictivity which will solve this problem, I reformulate the extensional definition of restrictive modification, so that the formats of the extensional and modal definitions of (non)restrictive modification can be uniformised.

\section{(18) restrictive modification}

A modifier $\mathrm{M}$ restrictively modifies a head $\mathrm{H}$ with respect to an individual $x$ and a situation $s(=\mathrm{r}-\bmod (\mathrm{M}, \mathrm{H}, x, s))$ iff

$\mathrm{M}_{s}(x) \wedge \mathrm{H}_{s}(x) \wedge$

$\exists x^{\prime}\left[\mathrm{H}_{s}\left(x^{\prime}\right) \wedge \neg \mathrm{M}_{s}\left(x^{\prime}\right)\right]$ 
According to this definition, there is at least one $x^{\prime}$ in $s$ that is $H$ but not $M$. This definition is extensional in the sense that only a single situation is taken into account. The reformulation of the definition of nonrestrictive modification is as follows:

\section{(19) nonrestrictive modification}

A modifier $\mathrm{M}$ nonrestrictively modifies a head $\mathrm{H}$ with respect to an individual $x$ and a situation $s(=n r-\bmod (\mathrm{M}, \mathrm{H}, x, s))$ iff

$\mathrm{M}_{s}(x) \wedge \mathrm{H}_{s}(x) \wedge$

$\forall x^{\prime}\left[\mathrm{H}_{s}\left(x^{\prime}\right) \rightarrow \mathrm{M}_{s}\left(x^{\prime}\right)\right]$

This definition states that every $x^{\prime}$ in $s$ that is $H$ is also $M$, and it is extensional in the same sense that only a single situation is considered.

These definitions differ from the ones in (10) in that they make the individual(s) described (here: $x$ ) an additional parameter of the definitions. ${ }^{16}$ Note that according to these definitions, nonrestrictive modification implies the lack of restrictive modification:

(20) $\operatorname{nr}-\bmod (\mathrm{M}, \mathrm{H}, x, s) \rightarrow \neg \mathrm{r}-\bmod (\mathrm{M}, \mathrm{H}, x, s)$ (for values of $x$ and $s$ ) (nonrestrictive modification implies the lack of restrictive modification)

Now, let us introduce the modal definition of restrictivity. The basic idea is that a modifier $\mathrm{M}$ is no longer restrictive (or nonrestrictive) tout court; instead, it is restrictive (or nonrestrictive) with respect to a particular modal base $\alpha$ (thus, $\alpha$ nonrestrictivity and $\alpha$-restrictivity).

(21) $\alpha$-restrictive modification

A modifier $\mathrm{M} \alpha$-restrictively modifies a head $\mathrm{H}$ with respect to an individual $x$ and a situation $s(=\mathrm{r}-\bmod +(\alpha, \mathrm{M}, \mathrm{H}, x, s))$ iff

$\mathrm{M}_{s}(x) \wedge \mathrm{H}_{s}(x) \wedge$

$\exists s^{\prime}\left[\alpha-\operatorname{acc}\left(s, s^{\prime}\right) \wedge \exists x^{\prime}\left[\mathrm{H}_{s^{\prime}}\left(x^{\prime}\right) \wedge \neg \mathrm{M}_{s^{\prime}}\left(x^{\prime}\right)\right]\right]$

This definition adds that there is an $s^{\prime}$ that is $\alpha$-accessible from $s$ such that there is an $x^{\prime}$ in $s^{\prime}$ which is $\mathrm{H}$ but not $\mathrm{M}$. The value for $\alpha$ may vary according to the situation. For example, in addition to 'evaluative', it may be 'stereotypical', 'prototypical', 'semantic', or arguably even 'realistic'.

Let us see now how this definition can be applied to our previous example (16b), repeated below.

\footnotetext{
${ }^{16}$ It is useful to do so in order to make individual(s) described available, so that we can refer to $\mathrm{it} /$ them. This also has the consequence that nonvacuity is guaranteed (because we are referring to particular individuals).
} 
b. Pierre m'a offert des fleurs horribles.

Pierre me-has offered INDEF flowers horrible

'Pierre offered me horrible flowers.'

Here, $\alpha$ would have a value like 'evaluative': there is an evaluative-accessible situation $s^{\prime}$ from $s$ such that there is an $x^{\prime}$ which is a flower (that Pierre offered me) in $s^{\prime}$ but not horrible in $s^{\prime}$. As we see, the definition of $\alpha$-restrictivity enables us to capture the intuition that in indefinites, post-head modifiers are 'contrastive', although they do not contrast individuals in the situation $s$, like standard restrictive modifiers do.

Notice that if $\alpha$ has the value 'totally realistic', then the only situation that is $\alpha$-accessible from $s$ is $s$ itself, in which case $\alpha$-restrictive modification reduces to restrictive modification. In general, though, for other values of $\alpha$, it is the access to situations other than $s$ that makes this definition modal.

A way to define the modal notion of nonrestrictive modification is as follows:

\section{(22) $\alpha$-nonrestrictive modification}

A modifier $\mathrm{M} \alpha$-nonrestrictively modifies a head $\mathrm{H}$ with respect to an individual $x$ and a situation $s(=\mathrm{nr}-\bmod +(\alpha, \mathrm{M}, \mathrm{H}, x, s))$ iff

$\mathrm{M}_{s}(x) \wedge \mathrm{H}_{s}(x) \wedge$

$\forall s^{\prime}\left[\alpha-\operatorname{acc}\left(s, s^{\prime}\right) \rightarrow\left(\mathrm{H}_{s^{\prime}}(x) \rightarrow \mathrm{M}_{s^{\prime}}(x)\right)\right]$

This definition adds that for every $s^{\prime}$ that is $\alpha$-accessible from $s$, if $x$ is $\mathrm{H}$ in $s^{\prime}$, then $x$ is $\mathrm{M}$ in $s^{\prime}$. Note, importantly, that we consider the same individual(s) in every $\alpha$-accessible $s^{\prime}$. Let us see how this definition applies to (16a) repeated below:

a. Pierre m'a offert d'horribles fleurs.

Pierre me-has offered INDEF horrible flowers

'Pierre offered me horrible flowers.'

Assuming again that the value of $\alpha$ is 'evaluative', we would obtain the result that in every evaluative-accessible situation $s^{\prime}$ from $s$, every flower in $s$ is also horrible in $s^{\prime}$. More elaborately, the flowers in $s$ are horrible in $s$, and they remain horrible in every evaluative-accessible situation $s^{\prime}$ from $s$. This definition of $\alpha$ nonrestrictivity captures the often reported intuition that in Romance languages, neutral modifiers in pre-nominal position are 'emphatic', present the description they convey as 'unquestionable', 'non-negotiable', 'beyond any doubt'.

Note that the definition in (22) does not require that all $x$ which are $H$ in $s$ are also $M$ in $s$. That is, $\alpha$-nonrestrictive modification does not imply nonrestrictive modification. Note also that if $\alpha$ were totally realistic, then $s$ itself would be the only $\alpha$-accessible situation, which would make the second line redundant: 


$$
\begin{aligned}
& \mathrm{M}_{s}(x) \wedge \mathrm{H}_{s}(x) \wedge \\
& \mathrm{H}_{s}(x) \rightarrow \mathrm{M}_{s}(x) \text { (this line is redundant) }
\end{aligned}
$$

This means that $\alpha$-nonrestrictive modification does not reduce to nonrestrictive modification if $\alpha$ is totally realistic: since nonrestrictive modification quantifies over every $x^{\prime}$ in $s$ that is $\mathrm{H}$, it entails $\alpha$-nonrestrictive modification if $\alpha$ is totally realistic, but not vice versa.

According to this account, the difference between (16a) and (16b) is that in (16a), I evaluate the particular flowers that Pierre offered me as horrible, saying that those particular flowers could not have been anything else than horrible, whereas in (16b), although I again evaluate the particular flowers that Pierre offered me as horrible, I say that there could have been other flowers (that he offered me) that would not be horrible.

Let us now see what happens in the following pair, where the modifier appears in a demonstrative NP:

$$
\begin{array}{lll}
\text { a. Regarde, } & \text { Pierre a choisi cet affreux bouquet! Et } \\
\text { look } & \text { Pierre has chosen this horrible bouquet and } \\
\text { pourtant, } & \text { tous les autres étaient magnifiques! } \\
\text { yet } & \text { all the others were wonderful }
\end{array}
$$

'Look, Pierre chose this horrible bouquet! And yet all the others were wonderful!'

b. Regarde, Pierre a choisi ce bouquet affreux! Et

look Pierre has chosen this bouquet horrible and

pourtant, tous les autres étaient magnifiques!

yet all the others were wonderful

'Look, Pierre chose this horrible bouquet! And yet all the others were wonderful!'

The context indicates that in both (24a) and (24b), affreux is restrictively interpreted (the other bouquets in $s$ are not affreux). But the two examples differ in terms of $\alpha$-(non)restrictive modification. In (24a), I evaluate the particular bouquet that Pierre chose as horrible, saying that this particular bouquet could not have been anything else than horrible, whereas in (24b), although I again evaluate the particular bouquet that Pierre chose as horrible, I say that there could have been another bouquet (that he chose) that would not be horrible.

Finally, $\alpha$-(non)restrictivity can also capture the difference between 'restrictive' vs. 'nonrestrictive' neutral manner adverbials. Let us take a French example (the previous English example (12) can be analysed the same way). 
a. Il a magnifiquement joué Pygmalion. he has wonderfully played Pygmalion 'He wonderfully played Pygmalion.'

b. Il a joué Pygmalion magnifiquement. he has played Pygmalion wonderfully 'He played Pygmalion wonderfully.'

The difference between (25a) and (25b) is that in (25a) ( $\alpha$-nonrestrictive reading), I evaluate the particular Pygmalion-playing event performed by Paul as wonderful, saying that this particular event could not have been anything else than wonderful, whereas in (25b) ( $\alpha$-restrictive reading), although I again evaluate the particular Pygmalion-playing event as wonderful, I say that there could have been another Pygmalion-playing event (performed by Paul) that would not be wonderful. ${ }^{17}$

These new definitions of $\alpha$-nonrestrictivity and $\alpha$-restrictivity are more complex than the standard (extensional) definitions of nonrestrictivity and restrictivity, and in particular, they do not contradict each other. Consequently, a modifier $M$ in combination with a head $\mathrm{H}$ may be both $\alpha$-nonrestrictive and $\alpha$-restrictive in a situation $s$ with respect to a value of $\alpha$.

Let me summarise the main points of the proposed account. For cases where $\llbracket \lambda x\left[\mathrm{M}_{s}(x) \wedge \mathrm{H}_{s}(x)\right] \rrbracket \subset \llbracket \mathrm{H}_{s} \rrbracket$, the extensional definitions of restrictivity and nonrestrictivity work fine. This is e.g. the case with definites; I proposed that in DPs of this kind, the extensional definitions have to apply. For cases where $\llbracket \lambda x\left[\mathrm{M}_{s}(x) \wedge \mathrm{H}_{s}(x)\right] \rrbracket=\llbracket \mathrm{H}_{s} \rrbracket$, the standard definitions of restrictivity and nonrestrictivity are too extensional; we then resort to the modal definitions of restrictivity and nonrestrictivity. The complementarity hypothesis holds for neutral modifiers in that in a pre-head position, a neutral modifier is restrictive and/or $\alpha$-restrictive, while in a post-head position, a neutral modifier is nonrestrictive and/or $\alpha$-nonrestrictive. Finally, a restrictive modifier can be $\alpha$-restrictive (as affreux in (24b)) or $\alpha$-nonrestrictive (as affreux in (24a)). Inversely, a nonrestrictive modifier can additionally be $\alpha$-restrictive (as e.g. horrible in (16b)), or $\alpha$-nonrestrictive (as e.g. horrible in (16a)).

\footnotetext{
${ }^{17}$ One could argue that the contrastive value of post-verbal manner adverbs does not originate from their $\alpha$-restrictive character, but from the fact that postverbal adverbials are focused (Bellert 1977, Ernst 2002, Abrusán 2012). I do not deny that focus (sometimes) participates in the contrastive effect, but it is not clear that it is always involved in restrictive modification in French. I thus prefer an account where $\alpha$-restrictivity is in principle independent from focus.
} 


\section{The nonrestrictive bias of evaluative predicates}

\subsection{Previous accounts}

Now that the concept of restrictivity has been clarified, I come back to what I called the hypothesis of the 'nonrestrictive bias' of evaluative predicates, that is the idea that evaluative predicates typically cannot be used restrictively. Recall that a standard observation supporting this claim is that in Romance languages, evaluative adjectives are often odd in postnominal position, at least in definites, cf. (1b).

To my knowledge, two accounts of this property have been proposed. The first is the one of Milner (1978), who already observes that the nonrestrictive bias shows up with a subset of evaluative predicates only, e.g. abominable 'horrible', horrible, affreux 'dreadful', divin 'divine', extraordinaire 'extraordinary' (his 'adjectifs affectifs', henceforth wonderful predicates). He distinguishes them from what he calls 'mixed' evaluative predicates, e.g. beau 'beautiful', inopportun 'inappropriate', fort 'strong' (henceforth beautiful predicates). Milner does not illustrate the difference between wonderful and beautiful predicates with regard to restrictivity, but here are some examples of mine; a-examples contain beautiful predicates, and b-ones wonderful predicates.

a. J'ai croisé la voisine sexy ce matin.

I have bumped into the neighbour sexy this morning

'I bumped into the sexy neighbour this morning.'

b. \#J'ai croisé la voisine époustouflante ce

I have bumped into the neighbour amazing this

matin.

morning

'I bumped into the amazing neighbour this morning.'

a. J'ai déposé l' article intéressant sur ton bureau.

I have left the paper interesting on your desk

'I left the interesting paper on your desk.'

b. \#J'ai déposé l' article passionnant sur ton bureau. I have left the paper fascinating on your desk

'I left the fascinating paper on your desk.'

Milner claims that the nonrestrictive bias is due to the fact that wonderful adjectives are pseudo-predicates. In line with the emotivist and expressivist tradition in moral philosophy, he assumes that they are devoid of any true semantic content and that copulative sentences that have a wonderful adjective as matrix predicate 
are neither true nor false but only 'express' the speaker's attitude. Since wonderful adjectives do not denote sets, they cannot be used restrictively. This purely expressive character is supposed to independently show up through other properties Milner attributes to wonderful predicates. A first property is that they cannot appear in true (non rhetorical) questions, cf. (28a), for Milner a direct consequence of the fact that words devoid of any true semantic content cannot be questioned. This should also explain why a wonderful predicate appearing in a which-phrase is interpreted outside it. For instance, Milner assumes that in (28b)-(28c), the implication conveyed by the adjective is interpreted as a comment of the speaker outside the scope of the question (Which houses did they build? Whatever they are, I take for granted that they are fastuous; which novels did you write? I know by advance that they are passionating). Thirdly, Milner claims that wonderful predicates are always speaker-oriented, as the contradiction of (28d) is supposed to show.

a. \# Habite-t-il une maison fastueuse? (Milner 1978:289) lives / $\mathrm{t} /$ he a house sumptuous 'Does he live in a sumptuous house?'

b. Quelles maisons fastueuses ont-ils construites? (id.:290) which houses sumptuous have they built 'Which sumptuous houses did they build?'

c. Quels romans passionnants avez-vous écrits? (ibid.) which novels passionating have you written 'Which fascinating novels did you write?'

d. \#Bien que ce film superbe passe depuis longtemps, although this film superb is on screen for a long time Jean $m$ ' a dit $q u$ ' il $n$ ' avait pas vu l' Jean me has told that he NEG have NEG seen the abominable Amarcord. (id.:300) horrible Amarcord

'Although this superb film is onscreen for a long time, Jean told me that he didn't watch the horrible Amarcord.'

I do not agree with Milner's description of facts. Firstly, even if the adjective's content in (28b) and (28c) can be attributed to the speaker, it does not have to be. For instance, it is attributed to the hearer under the most accessible interpretation of (29a). ${ }^{18}$ Secondly, the implication conveyed by wonderful predicates is

\footnotetext{
${ }^{18}$ The idea that in questions, evaluative predicates invite the hearer's opinion is found in various works dedicated to these predicates in the literature on relativism, cf. a.o. Lasersohn (2005),
} 
not necessarily interpreted outside the scope of verba dicendi. The contradiction of (28d) is due to the fact that abominable appears in a definite DP and would also arise if the evaluative predicate were replaced with a factual one. ${ }^{19}$ If the wonderful predicate appears in an indefinite, the contradiction vanishes, and this independently of the syntactic position of the adjective, cf. (29b).
a. Quels romans PASSIONNANTS as-tu eu l' occasion which novels passionating have you had the opportunity
de lire ces derniers mois?
to read these last months

'Which fascinating novels did you have the opportunity to read these last months?'

b. Pierre $m^{\prime}$ a dit $q u$ ' il avait lu un roman

Pierre me has told that he had read a novel ÉPOUVANTABLE/ un ÉPOUVANTABLE roman de Thomas

horrible a horrible novel of Thomas

Bernhard. Moi je les trouve tous excellents.

Bernhard me I them find all excellent

'Pierre told me that he read a horrible novel from Thomas Bernhard. I find them all excellent.'

Thirdly, even if I agree with Milner's observation that wonderful predicates are often strange in true questions, I do not think that this is due to the fact that their content being expressive, it has to be interpreted outside the scope of the illocutory operator. In the spirit of the account proposed in Martin (2006), I would claim that the problem is due to the mirative flavour of wonderful predicates. ${ }^{20}$ The claim that wonderful adjectives are mirative-like is supported by the fact that they require

Stephenson (2007) (I thank an anonymous reviewer for this point).

${ }^{19}$ Milner claims the contrary, but I am not convinced by his data since they are not built with a definite. For instance, the following example (built with a factual predicate) is indeed not contradictory but contains an indefinite in its first part:

(1) Jean m'a dit qu'un roman inachevé d'Hervé Bazin Vipère au poing lui avait beaucoup plu; pourtant ce roman est généralement considéré comme terminé. (p. 301)

'Jean told me that an unfinished novel from Hervé Bazin Vipère au poing pleased him a lot; however, this novel is generally considered as finished.'

${ }^{20}$ Mirative constructions express an emotion of the speaker caused by the fact that her expectations are exceeded in front of an unanticipated/novel information (see Rett and Murray 2013 for a review of miratives across constructions and languages). Exclamatives are typical mirative constructions (see e.g. Castroviejo 2006, Merin and Nikolaeva 2008, Peterson under review). 
an exclamative prosody and all indicate that an extreme or at least unexpectedly high degree is achieved. The problem they raise in true questions can be accounted for as follows: it is pragmatically odd to ask whether an extreme degree is obtained and expectations were consequently exceeded in a context where it is not even assumed that a high or very high degree is obtained. An evidence for this is that the problem vanishes in a context where the obtention of a very high degree is taken for granted, cf. (30). ${ }^{21}$

a. On est bien d'accord que sa maison est très belle. we are well of agreement that his house is very beautiful Mais est-ce qu' elle est FASTUEUSE? but is it that it is sumptuous 'We agree that his house is very beautiful. But is it sumptuous?'

b. On est bien d'accord que son discours était très we are well of agreement that his speech was very mauvais. Mais est-ce qu' il était ABOMINABLE? bad but is it that it was horrible 'We agree that his speech was very bad. But was it horrible?'

The second account of the nonrestrictive bias of evaluative predicates I am aware of is the one of Umbach (2006, 2012a,b). Interestingly, Umbach also distinguishes between the same two classes of evaluative predicates as Milner, the schön 'beautiful' predicates and the wunderbar 'wonderful' ones. She makes a similar observation for German as Milner for French, namely that the former get the restrictive reading much more easily.

Umbach distinguishes evaluative predicates from factual ones by the type of propositions they denote: the former convey ethical/aesthetical propositions that are not empirically testable, ascribed by the speaker. But she differentiates wonderful from beautiful predicates by the type of aesthetical/ethical judgments they convey. Building on the Kantian distinction between universal and subjective aesthetical/ethical judgements, Umbach proposes that while beautiful predicates may

\footnotetext{
${ }^{21}$ That wonderful predicates are also odd under negation (as noted by Milner too) can be accounted for the same way:

a. \# Je n'ai pas acheté une voiture MAGNIFIQUE. 'I did not buy a wonderful car.'

b. J'ai acheté une belle voiture, on est bien d'accord. Mais je n'ai pas acheté une voiture MAGNIFIQUE. 'I bought a nice car, we agree on that matter. But I did not buy a wonderful car.'
} 
be used to convey universal judgements, wonderful ones can only convey subjective ones. When used to convey a universal judgment, beautiful predicates do not project an experiencer argument, while wonderful ones always do. Universal evaluative judgments partly 'mimic' empirical judgments in that they are normative: they rely on shared norms providing a standard that allow to define 'objectively' what counts as beautiful. ${ }^{22}$ Therefore, universal evaluative judgments are truly 'debatable' (that is, the question whether $x$ is beautiful can give rise to a genuine, non faultless disagreement) and are intended to enter the common ground. On the other hand, subjective evaluative judgments are purely private: they are only intended to reflect the subject's attitude, and therefore do not target the common ground. Rather, they are stored in what Farkas and Bruce (2010) call individual discourse commitments (sets of propositions to which a participant publicly commits, but which are not in the common ground). Judgments of this type give rise to 'faultless disagreement'.

Umbach further assumes that in order to be restrictive, a modifier should trigger alternatives and define a 'commonly accepted cut-off point': the denotation of a restrictive modifier and of its complement has to be commonly agreed upon so that it can be used to narrow down the denotation/reference of the modified noun phrase. The idea, then, is that since wonderful predicates systematically convey subjective judgments, they cannot be used restrictively because they are by definition used to denote privately defined sets. The participants are not supposed to know how the speaker defines the set of wonderful things. Therefore, using wonderful predicates restrictively is odd because it is uncooperative.

\subsection{Refining the empirical picture}

I agree with Umbach's characterisation of the two classes of evaluative adjectives. But a general problem raised by the two accounts just presented is that the nonrestrictive bias is not always at play. In some contexts indeed, wonderful adjectives can have a restrictive reading. This explains why they so often appear in post-head position in languages like French. This section describes in detail the contexts in which evaluative predicates can appear in post-head position in French and the associated readings. The collected data are summarised in Table 3 at the end of this section. They will be accounted for in Section 3.3.

Firstly, under a certain condition described below, wonderful predicates can

\footnotetext{
${ }^{22}$ Note that under Umbach's account, universal evaluative judgments, although 'objectivable' through the set of norms they rely on, still remain subjective in that the norms are not presupposed in the context but proposed by the speaker. This is how I understand Umbach's proposal that subjective propositions conveyed by evaluative predicates are always interpreted metalinguistically, in the sense of Barker (2002): the speaker who asserts the universal judgment The flowers are beautiful is also making a proposal about the standard of beauty in the context.
} 
be restrictive when they convey an at-issue content directly addressing a 'question under discussion' (QUD). ${ }^{23}$ For instance, in (31)-(33), the implication conveyed by the adjective under narrow focus answers an (explicit or implicit) whichquestion, and is thus under discussion ((33) is taken from the Internet).

a. Quels vêtements a-t-il jetés? which clothes has he thrown away

'Which clothes did he throw away?'

b. Il ajeté les vêtements HORRIBLES, et gardé les he threw away the clothes horrible and kept the autres

others

'He threw the horrible clothes away, and kept the others.'

a. Quel genre de femmes tu aimes? which kind of women you like 'Which kind of women do you like?'

b. Ah, moi, je n'aime que les femmes MAGNIFIQUES! ah me I NEG like only the women gorgeous 'Ah, me, I only like gorgeous women!'

(33) Quand je commence à lire un roman intéress[a]nt, je ne when I begin to read a novel interesting I NEG lui consacre que les moments DÉLICIEUX de la vie. it-DAT devote only the moments delicious of the life 'When I begin to read an interesting novel, I only devote the delicious moments of life to it.'

In these examples, wonderful adjectives also clearly contrast a set of entities out of a larger set, which can be contextual (cf. (31)) or maximal (cf. (32) and (33)). They are therefore also restrictive. Note that in (32)-(33), the wonderful predicates are in the focus of que 'only', which suggests that they can induce alternatives. Thus, although arguably, wonderful predicates are typically used to denote 'privately defined sets' (i.e. sets whose denotation is private, not commonly agreed upon; cf. Umbach's proposal), they can nevertheless trigger alternatives and be used restrictively. More generally, a modifier can be restrictively used although

\footnotetext{
${ }^{23}$ Under Roberts (1996)'s definition, the question under discussion (QUD) is the question that determines the discourse topic. Focus indicates what is the QUD: it determines which part of the sentence corresponds to what is the information asked for by the question.
} 
the denotation of this modifier and of its complement is not commonly agreed upon.

There is a restriction on this use though. Indeed, wonderful predicates can be restrictive only if they have an additional discourse role, typically an explanatory function. This is the case if the implication $p$ conveyed by the modifier explains the proposition $q$ denoted by the rest of the sentence. This is true in (31)-(33): (31b) suggests that the subject's referent got rid of these clothes because they were horrible, etc. If the context makes the explanatory function unlikely, wonderful predicates are again deviant with standard definites in post-nominal position, even if they address the QUD. For instance, the following examples (34) are strange, unless it is understood that $p$ (the vases $x$ are wonderful) explains $q$ (the vases $x$ should be put on the buffet):

a. Quels vases tu m'as dit de déposer sur le buffet?

'Which vases did you tell me I should put on the buffet?'

\# Dépose sur le buffet les vases MAGNIFIQUES.
put

'Put on the buffet the wonderful vases!'

b. Quels livres tu m'as dit que je devais te passer?

'Which books did you tell me I should give you?'

\# Passe-moi les livres HORRIBLES!
give me the books horrible
'Give me the horrible books!'

Interestingly, under the causal interpretation induced in (31)-(33), the Judge does not have to be the speaker, but can also be the hearer or somebody else. For instance, the answer in (31b) can very well be understood as 'He got rid of the clothes that are horrible according to him'. This raises an issue for those accounts that rely on the premise that wonderful $N$ systematically defines the set of wonderful $\mathrm{N}$ according to the speaker.

A second point to note about the difficulty for wonderful predicates to get a restrictive reading is that it is limited to 'standard' restrictivity. Wonderful predicates have no problem to get the $\alpha$-restrictive reading: they have no difficulty to appear in post-head position with indefinites, cf. (35), or with adverbials, cf. (36).

(35) Je vais lui acheter des fleurs magnifiques.

I will him/her buy INDEF flowers magnificent

'I will buy her magnificent flowers.' 
(36) Pierre a exécuté cette sonate magnifiquement.

Pierre has played this sonata marvelously

'Pierre played this sonata marvelously.'

The next relevant new observation is that in French, wonderful adjectives can appear in post-nominal position with a (standard) nonrestrictive reading in first mention definites. First-mention definites introduce a set of $\mathrm{MH}$ without presupposing the existence of a superset of $\mathrm{H}$, exactly like indefinites (except that they still presuppose the uniqueness of the referent). Definites modified by what Hawkins (1978) calls an 'establishing relative' are of this kind. I give a relevant example in (37b).

a. \# Regarde le vase MAGNIFIQUE! look the vase wonderful

'Look at the wonderful vase!'

b. Regarde le vase MAGNIFIQUE que Chuck vient de look the vase wonderful that Chuck comes to m'offrir!

PRN.1SG.DAT offer

'Look at the wonderful vase Chuck just gave me!'

With Hawkins' establishing relatives, the referent is then introduced within the total definite NP, rather than prior to the definite NP, and it is not extracted from a contextual superset. So the vase described in (37b) is understood as the only contextual vase. Therefore, magnifique is (standardly) nonrestrictive, exactly as with non-partitive indefinites. But I take it to be $\alpha$-restrictive: (37b) differs from its variant with a prenominal modifier in that it suggests that there is an evaluativeaccessible situation $s^{\prime}$ from $s$ such that there is an $x^{\prime}$ which is a vase that Chuck offered me but that is not wonderful in $s,{ }^{24}$

\footnotetext{
${ }^{24}$ With a prenominal modifier instead of a postnominal one, (37b) suggests that the particular vase that Chuck offered me could not have been anything else than wonderful.

Another similar contrast, taken from Martin (2006), is given in (1) below: the relative is establishing in (1a), but not in (1b):

(1) a. Pierre observait les clients du bar. La femme MAGNIFIQUE qui venait d'entrer commanda une bière.

'Pierre was observing the customers of the bar. The WONDERFUL woman who just entered ordered a beer.'

b. Pierre observait les clients du bar. \#La femme MAGNIFIQUE qui était blonde commanda une bière.

'Pierre was observing the customers of the bar. The WONDERFUL woman who was blond ordered a beer.'
} 
Note that (37b) is acceptable although the wonderful predicate does not have any explanatory function. This function is therefore required only if the wonderful adjective has the (standard) restrictive reading as in (31)-(33), something that one should explain too.

Finally, another desirable goal is to provide a unified explanation for the previous observations and the difficulty of wonderful predicates to be used in anaphoric definite NPs even if used nonrestrictively, something that both Milner and Umbach observe independently. Umbach illustrates this through her example (38). In the answer (38b), the vase referred to is the only vase in the situation; the modifier is consequently nonrestrictive according to the standard definition (10).

a. Sue: Guck mal, Chuck hat mir eine wunderbare Vase look just Chuck has me a wonderful vase geschenkt.

offered

'Look, Chuck offered me a wonderful vase.'

b. Bob: \#Ich helfe dir gleich. Stell die wunderbare Vase

I help you soon put the wonderful vase
schon mal auf das Büffet.
already just on the buffet

'I'll help you in a minute. Put the wonderful vase on the sideboard.'

Umbach (2006) suggests that the oddity of (38b) is due to the fact that wonderful predicates are expressives, and as such, not only take widest scope but are also 'plugged by the turn they are used in': when picked up by a discourse participant (Bob) different from the speaker (Sue), their interpretation is still linked to the former speaker (Sue). This would explain the fact that (38b) seems like an ironic quote.

However, as we saw above, several facts suggest on the contrary that wonderful predicates differ from expressives à la Potts (2005): they are not always speaker-oriented, do not systematically take widest scope, etc. (cf. the discussions of examples (28)-(29) above). Also, according to my German informants, the problem of (38b) tends to disappear when the definite is replaced with a demonstrative, something that is not obviously expected if the difficulty is due to the expressive character of wunderbar.

The French translations of Umbach's example raise an independent problem that arises not only with evaluative modifiers, but also with factual adjectives. The problem is that the demonstrative tends to win in the competition with the definite when the entity of type $N$ (here the vase) is not contrasted with an entity of another type, cf. Corblin (1987). So for this independent problem to be controlled 
for in the translations (39) of Umbach's example, I introduce a contrast between the vase and an object of another type in the context.

a. Regarde un peu, Chuck m' a offert une bouteille de look a bit Chuck me has offered a bottle of vin et un vase MAGNIFIQUE! wine and a vase wonderful 'Look, Chuck offered me a bottle of wine and a wonderful vase!'

b. \# Je t'aide dans une minute. En attendant, installe le I you help in a minute while waiting, put the vase MAGNIFIQUE sur le buffet. vase wonderful on the sideboard 'I'll help you in a minute. Put the wonderful vase on the sideboard.'

c. Je t'aide dans une minute. En attendant, installe le I you help in a minute while waiting put the \# magnifique/(OK) MAGNIFIQUE vase sur le buffet. wonderful wonderful vase on the sideboard 'I'll help you in a minute. Put the wonderful vase on the sideboard.'

In such examples, wonderful predicates are indeed odd in a postnominal position, cf. (39b). This is true whether the adjective is accented or not. ${ }^{25}$ In pre-nominal position, things are more complex; cf. (39c). If magnifique is used in (39c) as a simple repetition of the previous description (the by default interpretation when the predicate is not accented), the example gives rise to the same funny effect as the one described by Umbach. However, if it is understood as a (new) commitment of the speaker, communicating she agrees with her addressee (the by default interpretation when the predicate is accented), the problem vanishes.

Table 3 summarises the observations collected throughout this section with regard to the acceptability of wonderful predicates in pre- and post-head positions in French; the first column gives the type of constituents the modifier is part of (DPs or VPs, types of DPs), the second and third indicate the acceptability in prehead position $(\mathrm{MH})$ and the associated readings, and the last two provide the same information for the post-head (HM) position.

Two conclusions can be brought out from Table 3 and the previous observations: (i) the restrictive reading is not alone responsible for the unacceptability

\footnotetext{
${ }^{25}$ French elative adjectives like magnifique 'magnificent', énorme 'enormous' very often seem to require prosodic prominence. This accent does not have to correspond to the 'standard' focus marking the information asked for by the QUD; it rather generally marks emphasis, emotiveness, etc. See already Bolinger (1965) on the idea that accent placement can not only be determined by standard focushood, but also by other factors like emotiveness.
} 


\begin{tabular}{|l|l|l|l|l|}
\hline & \multicolumn{2}{l|}{$\mathrm{MH}$} & $\mathrm{HM}$ \\
\hline \hline standard definite DPs & $\mathrm{OK}$ & $\mathrm{NR}$ & \#/OK & $\mathrm{R}$ \\
\hline anaphoric definite DPs & \#/ OK & $\mathrm{NR}$ & $\#$ & $\mathrm{NR}$ \\
\hline non-part. indefinites DPs & $\mathrm{OK}$ & $\mathrm{NR}, \alpha-\mathrm{NR}$ & $\mathrm{OK}$ & $\mathrm{NR}, \alpha-\mathrm{R}$ \\
\hline VPs (adverbials) & $\mathrm{OK}$ & $\mathrm{NR}, \alpha-\mathrm{NR}$ & $\mathrm{OK}$ & $\mathrm{NR}, \alpha-\mathrm{R}$ \\
\hline first mention definite DPs & $\mathrm{OK}$ & $\mathrm{NR}, \alpha$-NR & $\mathrm{OK}$ & $\mathrm{NR}, \alpha-\mathrm{R}$ \\
\hline
\end{tabular}

Table 2: Distribution of wonderful predicates in pre- and post-head position in French

of wonderful predicates in postnominal position (another factor is the absence of an additional discourse function, like the explanatory function); (ii) wonderful predicates are sometimes odd in prenominal position even if they receive the nonrestrictive reading (as in anaphoric definites). This suggests that the nonrestrictive bias of these predicates is the consequence of another of their properties.

\subsection{New proposal}

I claim that the restrictions just collected on the uses of evaluative predicates originate from a single rule. Put simply, this rule states that the predicative content of an evaluative predicate must matter: those cannot be used regardless of the description they provide, precisely because of their evaluative nature. On this point, evaluative modifiers drastically differ from factual ones. It is a trivial observation that a factual adjective like blond can be used regardless of its description, as a simple 'pointing stick', for the simple purpose of tracking reference (e.g. designating the single blond element of a contextual set or establishing an anaphorical link to a previous discourse referent). That $x$ is blond can be totally irrelevant in the discourse, and the speaker does not have to care about $x$ 's blondness to use blond. This echoes a familiar assumption about the way the descriptive content functions in standard definites. As Wettstein (1991:36) puts it:

Consider the referential use [of definite descriptions]; there are contexts in which a speaker wants to draw his audience's attention to an entity, perhaps one visually present to both speaker and audience, in order to go on and, for example, predicate something of it. It is irrelevant to the purposes of the speaker, in many such cases, how the attention of the audience is directed to the referent. Pointing with one's finger or uttering a proper name would do as well as some elaborate description. (italics mine) 
My proposal (summarised below in (40)) is that with evaluative predicates, the speaker must care about the description used - it has to be relevant for the purposes of the speaker: one cannot use evaluative predicates only in order to refer to the right referent. Since beautiful predicates behave like regular predicates when they express universal judgements (Umbach 2012a), they can be used as factual adjectives, too.

In (40b) I state more precisely what I mean when saying that the predicative content of a wonderful predicate 'must matter':

(40) a. Wonderful predicates cannot be used for a pure referential/denotational purpose only. Their descriptive content has to be relevant for the discourse.

b. The descriptive content $p$ of a predicate (e.g. ' $x$ is wonderful') is presented as relevant for the discourse when

i. $p$ provides a new description of the referent/denotation given the current common ground, or

ii. $p$ is positively/negatively relevant for the proposition $q$ described by the rest of the sentence (i.e. the sentence without the modifier). In case $p$ explains $q, p$ is positively relevant for $q$; in case $p$ contrasts with $q, p$ is negatively relevant for $q$.

The relation of positive and negative relevance can be more formally defined through the notion of relevance of Merin (1999), repeated in (41) (' $P^{i}(p)$ ' gives the probability of $p$ in the epistemic context $i$ ).

(41) $p$ is positively relevant for $q$ in the context $i$ iff $\left[P^{i}(p \mid q)>P^{i}(q)\right]$ $p$ is negatively relevant for $q$ in the context $i$ iff $\left[P^{i}(p \mid q)<P^{i}(q)\right]$

For instance, in (31), the fact that the clothes in question were horrible $(p)$ is presented in the context $i$ as positively relevant (as a positive argument) for the fact that they had been thrown away $(q)$. But in (34), he fact that the vase in question is horrible $(p)$ is by default presented as totally irrelevant (neither as a positive argument nor as a negative one) for the fact that it should be put on the buffet $(q)$.

Let us see now how (40) explains the data. Firstly, (40) explains why post-head wonderful modifiers are always unproblematic with non-partitive indefinites, firstmention definites and adverbials. In these three cases, wonderful(ly) modifiers provide a new description of the referent in the context, since the referent is each time newly introduced by the VP or DP that contains the modifier. This description is therefore always potentially relevant for the discourse as defined in (40). Since the newness of the description suffices to make it relevant, the description $p$ conveyed by the modifier does not need to be relevant for $q$, the propositional 
content of the rest of the sentence (as e.g. through an explanatory use).

Another related fact that we explain for free is that wonderful adjectives are always acceptable in demonstratives, in pre- and post-nominal positions. Compare for instance (39b) repeated below with (42b), completely uncontroversial:

a. Regarde un peu, Chuck m' a offert une bouteille de look a bit Chuck me has offered a bottle of vin et un vase MAGNIFIQUE! wine and a vase wonderful 'Look, Chuck offered me a bottle of wine and a wonderful vase!'

b. \# Je t'aide dans une minute. En attendant, installe le I you help in a minute while waiting put the vase MAGNIFIQUE sur le buffet. vase wonderful on the sideboard 'I'll help you in a minute. In the meantime, put the wonderful vase on the sideboard.'

a. Sue: Regarde un peu, Chuck m' a offert un vase look a bit Chuck me has offered a vase MAGNIFIQUE! wonderful 'Look, Chuck offered me a wonderful vase!'

b. Bob: Waouw, super! Je t' aide dans une minute. En wow great I you help in a minute while attendant, installe ce MAGNIFIQUE vasel ce vase waiting put this wonderful vase this vase MAGNIFIQUE sur le buffet par exemple. wonderful on the buffet for instance 'Wow, great! I help you in a minute. In the meantime, put this wonderful vase on the buffet for instance.'

It suffices to admit with Corblin (1987) that demonstratives systematically present the description they provide of the referent as new. Even in cases where this description is already assumed in the common ground, demonstratives reintroduce it, as if it were new.

We can also explain why post-nominal wonderful adjectives are odd in anaphoric definites. Let us come back to (39b). One the one hand, given that we deal with an anaphoric definite, the context makes clear that there is only one vase in the context: magnifique should be interpreted nonrestrictively. But on the other hand, 
since the neutral modifier appears post-nominally in a definite, it must be restrictive (i.e. contrasts the vase with another contextual vase); cf. our claim at the end of Section 2.1. The contradiction between these two requirements explains the oddity of (39b). ${ }^{26}$

Next, we can also account for why pre-nominal wonderful adjectives are sometimes acceptable, and sometimes not in anaphoric definites. In Umbach's vase example (38), the description provided by the predicate is already given in the context. It has additionally no explanatory value. If it is used as a simple repetition of the previous description, the adjective is presented as a mere 'pointing stick', used regardless of its descriptive content, directly violating (40). We predict however that in anaphoric definite DPs of this kind, wonderful predicates should be more at ease once the description is new, which can be the case if they do not form part of the previous mention that serves as an antecedent for the anaphoric definite. This prediction is in fact correct. Firstly, (43) is acceptable:

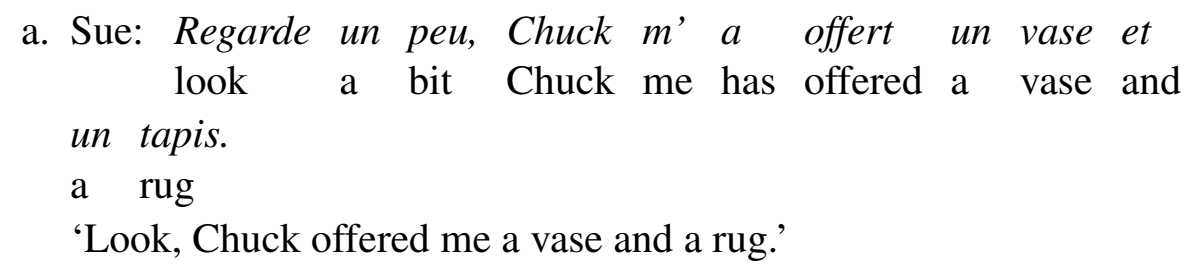

a. Sue: Regarde un peu, Chuck $m^{\prime}$ a offert un vase et look a bit Chuck me has offered a vase and un tapis.

a rug

'Look, Chuck offered me a vase and a rug.'

b. Bob: Waouw, super! Je t' aide dans une minute. En wow nice I you help in a minute while

attendant, installe le MAGNIFIQUE vase sur le buffet par waiting put the wonderful vase on the buffet for exemple.

instance

'Wow, nice! I'll help you in a minute. In the meantime, put the WONDERFUL vase on the buffet for instance.'

Secondly, in (39c) above, when magnifique is accented, it can also be understood as conveying a new description of the referent: the emphasis indicates that the vase is now described as wonderful according to the speaker, and not according to the addressee (the Judge/Experiencer does not have the same value as in the previous description). Since the description conveyed by the modifier is then understood as new, (40) is respected and the problem vanishes.

Another prediction of the account proposed here is that in anaphoric definite DPs, wonderful predicates should be acceptable when an explanatory use is plausible, even if the description $p$ conveyed by the predicate is already familiar in the

\footnotetext{
${ }^{26}$ Note that a problem similar to the one in (39b) would arise if horrible were post-nominal in (44a) below.
} 
common ground. The acceptability of (44a) below confirms this prediction (that $x$ is horrible can very well explain that $x$ is put on eBay). Note that in this example, when horrible is used for the second time, it cannot be understood as a new description of the antecedent (as this was the case in (39c)), since the Experiencer has to be the same for the two mentions.

The explanatory use is by contrast not plausible in (44b), therefore showing the same problem as Umbach's example.

a. Pour Noël, j' ai reçu un vase horrible et un for Christmas I have received a vase horrible and a tapis tout aussi horrible. J' ai déjà mis l' rug all equally horrible I have already put the HORRIBLE vase à vendre sur eBay, mais je n' en horrible vase to sell on eBay but I NEG of it espère pas grand-chose. hope NEG big thing 'For Christmas, I received a horrible vase and an equally horrible rug. I have already put the HORRIBLE vase on sale on eBay, but I do not hope much out of it.'

b. Regarde, pour Noël, j' ai reçu un vase horrible look for Christmas I have received a vase horrible et un tapis tout aussi horrible. \# Tu peux tenir l' and a rug all equally horrible you can hold the HORRIBLE vase une seconde? horrible vase one second 'Look, for Christmas, I received a horrible vase and an equally horrible rug. Can you please take the HORRIBLE vase for one second?'27

\footnotetext{
${ }^{27}$ Unsurprisingly, the same facts hold for wonderfully adverbials. If used purely anaphorically, independently of their description content, they are odd, as shown in (45a). However, if they are positively relevant for the rest of the sentence (e.g. they get the explanatory use), the problem vanishes, cf. (45b).

(45) a. Il a exécuté cette sonate MERVEILlEusement. \# Pendant qu'il a MERVEILLEUSEMENT joué, j'ai fait la vaisselle. 'He played this sonata wonderfully. While he had been wonderfully playing, I washed the dishes.'

b. Il a exécuté cette sonate MERVEILlEUSEMENT. Comme il a MERVEILlEUSEMENT joué, le jury s'est extasié et il a reçu le premier prix.

'He played this sonata wonderfully. Since he wonderfully played, the committee was ecstactic and he received the first Prize.'
} 
Finally, we can account for why wonderful predicates are acceptable in prenominal position in standard definites, cf. ex. (1a) repeated below. In examples of this kind, contrary to what we had in Umbach's vase example, the description $p$ conveyed by the adjective is not explicitly presented as known in the common ground, since it is not introduced through a previous mention that serves as an antecedent for the definite. It is thus possible to assume that $p$ is newly introduced in the common ground. The rule (40b) is therefore respected, and no problem arises:

a. J'ai vu l'affreux voisin ce matin.

I have seen the horrible neighbour this morning

'I saw the horrible neighbour this morning.'

b. \#J'ai vu le voisin affreux ce matin.

I have seen the neighbour horrible this morning

'I saw the neighbour horrible this morning.'

Finally, we can also explain the problem raised by wonderful predicates in the post-nominal position of standard definites, cf. (1b). In Section 2.1, I claimed that in this configuration, the modifier must have the standard restrictive reading. This means that the speaker uses the modifier in order to point to the right referent (the right neighbour into the superset of neighbours). But in order for this strategy to be presented as realistic, the description $p$ conveyed by the modifier must be presented as familiar to the addressee; otherwise, how could the addressee be able to track reference with the help of affreux? Therefore, $p$ cannot be presented as new in the common ground. The rule (40b) is then ceteris paribus violated, which explains the problem of (1b).

However, if the descriptive content $p$, although presented as shared, has an explanatory use, we are again insured that it is relevant for the discourse. The rule (40a) is then not violated anymore, since the adjective is not used for the single purpose of narrowing down the denotation out of a superset. This explains why (31)-(33) are acceptable (the explanatory use is then plausible), whereas (1b) remains odd (this use is here unlikely).

The description $p$ conveyed by the modifier is also relevant for the propositional content $q$ denoted by the rest of the sentence when the rhetorical relation Contrast (as defined by Asher and Lascarides 2003) takes place between the two. In that case, $p$ is negatively relevant to $q$. This licences the anaphoric use of wonderful(ly) modifiers too, as shown by the acceptability of (46) (for adverbials).

(46) Il a exécuté cette sonate MERVEILLEUSEMENT. Mais alors qu'il a MERVEILLEUSEMENT joué, son accompagnant a été vraiment horrible.

'He played this sonata wonderfully. But while he wonderfully played, his co-player really played in a horrible way.' 


\section{Conclusions}

In its first part (Section 1-2), this paper showed that the strong version of the complementarity hypothesis (in Romance, pre-head modifiers get the nonrestrictive interpretation only, while post-head modifiers receive the restrictive interpretation only) can be saved for neutral modifiers once admitted that restrictive modifiers can be defined either in a pure extensional way (as I claim they have to be in standard definites) or with respect to a particular modal base.

The second part of this paper (Section 3) addresses the nonrestrictive bias of evaluative predicates. I adopted Umbach's characterisation of the two classes of evaluative predicates, beautiful and wonderful ones, and Umbach/Milner's observation that the nonrestrictive bias is mostly salient within the second class. It was then shown that the two crucial assumptions of previous accounts, namely that wonderful predicates, qua expressives, are always speaker-oriented and cannot induce alternatives, have to be given up. After having compared the contexts where the restrictive reading of wonderful predicates is unacceptable with those where it is in fact unproblematic, I proposed a unified account of old and new data, where the problem sometimes raised by wonderful predicates in post-head position is seen as the consequence of the violation of a rule governing their use. According to this rule, the implication conveyed by wonderful has to be presented as relevant for the discourse (which is the case when $p$ is new or is a positive/negative argument for the proposition $q$ denoted by the rest of the sentence), differently from what happens with factual predicates.

\section{Acknowledgments}

I would like to thank four anonymous reviewers for their extremely valuable comments on two previous versions of this paper, as well as Arndt Riester, Giorgos Spathas and Carla Umbach for very helpful discussions. Also, I am extremely grateful to Chris Piñón for his valuable suggestion to appeal to modal definitions of (non)restrictivity and for extensive exchanges on the way modal (non)restrictivity should be defined. Finally, I thank Elena Castroviejo and Berit Gehrke for their editorial work. This work is part of the project B5 of the Stuttgart Collaborative Research Center (SFB) 732 Incremental Specification in Context and the project MOSCA (At the intersection of modification and scalarity: the semantic mapping of scale structure onto the interpretation of modifiers) of the Spanish Ministerio de Economia y Competitividad, Ref. FFI2012-34170, 20132016. Financial support by the Deutsche Forschung Gemeinschaft is kindly acknowledged.

Abeillé, A., Godard, D., 1999. La position de l'adjectif épithète en français: le poids des mots. Recherches linguistiques de Vincennes 28, 9-32. 
Abrusán, M., 2012. A note on quasi-presuppositions and focus. Journal of Semantics 30, 257-265.

Alexiadou, A., 2001. Adjective syntax and noun raising: word order asymmetries in the DP as the result of adjective distribution. Studia Linguistica 55, 217-248.

Asher, N., Lascarides, A., 2003. The Logics of Conversation. Cambridge University Press, Cambridge.

Bach, E., 1974. Syntactic Theory. Holt, Rinehart and Winston, New York.

Barker, C., 2002. The dynamics of vagueness. Linguistics and Philosophy 25, 136.

Bellert, I., 1977. On semantic and distributional properties of sentential adverbs. Linguistic Inquiry, 337-351.

Bolinger, D., 1965. Forms of English: Accent, Morpheme, Order. Harvard University Press, Cambridge.

Bouchard, D., 1998. The distribution and interpretation of adjectives in French: a consequence of bare phrase structure. Probus 10(2), 139-183.

Cabredo-Hofherr, P., in prep. Weak definite articles with restrictive relative clauses. In: Cabredo-Hofherr, P., Zribi-Hertz, A. (Eds.), Articles and nominal reference: Languages with and without articles.

Castroviejo, E., 2006. Wh-Exclamatives in Catalan. Ph.D. thesis, Universitat de Barcelona.

Castroviejo, E., 2008. Adverbs in restricted configurations. In: Bonami, O., Cabredo-Hofherr, P. (Eds.), Empirical Issues in Syntax and Semantics 7. pp. 53-76.

URL http: //www.cssp.cnrs.fr/eiss7/

Castroviejo, E., Schwager, M., 2008. Amazing DPs. In: Friedman, T., Ito, S. (Eds.), Proceedings of SALT XVIII. Ithaca, NY, pp. 176-193.

Cinque, G., 2003. The Dual Source of Adjectives and XP vs. N-Raising in the Romance DP, handout, NELS 34.

Cinque, G., 2010. The Syntax of Adjectives: a Comparative Study. MIT Press, Cambridge, MA.

Corblin, F., 1987. Indéfini, défini et démonstratif: constructions linguistiques de la référence. Droz, Genève.

Demonte, V., 1999. Clases de adjetivos. La posición del adjetivo en el SN. In: Gramática descriptiva de la lengua española. Espasa Calpe, Madrid, pp. 129215.

Demonte, V., 2005. Merge of Adjectives in DP and Interface Conditions, ms, Universidad Autónoma de Madrid.

Demonte, V., 2008. Meaning-form correlations and adjective position in Spanish. In: McNally, L., Kennedy, C. (Eds.), Adjectives and Adverbs: Syntax, Semantics, and Discourse. Oxford University Press, Oxford, pp. 71-100.

Enç, M., 1991. The semantics of specificity. Linguistic Inquiry 22, 1-25. 
Ernst, T., 2002. The Syntax of Adjuncts. Cambridge University Press, Cambridge. Fabricius-Hansen, C., 2009. Überlegungen zur pränominalen Nicht-Restriktivität. Linguistische Berichte, 89-110.

Farkas, D., Bruce, K., 2010. On reacting to assertions and polar questions. Journal of Semantics 27, 81-118.

Forsgren, M., 1978. La place de l'adjectif épithète en français contemporain, étude quantitative et sémantique. Almqvist \& Wilksell, Stockholm.

Geuder, W., 2000. Oriented Adverbs. Ph.D. thesis, Universität Tübingen.

Göbbel, E., 2007. Focus and marked positions for VP adverbs. In: Winkler, S., Schwabe, K. (Eds.), On Information Structure, Meaning and Form. John Benjamins, Amsterdam/Philadelphia, pp. 275-300.

Harris, J., 1995. The syntax and morphology class marker suppression in Spanish. In: Zagona, K. (Ed.), Grammatical Theory and Romance Languages. John Benjamins, Amsterdam, pp. 99-122.

Hawkins, J., 1978. Definiteness and Indefiniteness: A Study in Reference and Grammaticality Prediction. Croom Helm, London.

Heny, F., 1973. Sentence and predicate modifiers in English. In: Kimball, J. (Ed.), Syntax and Semantics 2. Seminar Press, New York and London, pp. 217-245.

Katz, J., 2008. Romance and restriction, ms, MIT.

Kennedy, C., t.a. Two kinds of subjectivity, to appear in Huitink, J. and C. Meier (Eds), Subjective Meaning.

Lasersohn, P., 2005. Context dependence, disagreement, and predicates of personal taste. Linguistics and Philosophy 28, 643-686.

Marchis, M., Alexiadou, A., 2009. On the distribution of adjectives in Romanian: the cel construction. In: Aboh, E., van der Linden, E., Quer, J., Sleeman, P. (Eds.), Romance Languages and Linguistic Theory. Benjamins, Amsterdam, pp. 161-178.

Martin, F., 2006. Prédicats statifs, causatifs et résultatifs en discours. Sémantique des adjectifs évaluatifs et des verbes psychologiques. Ph.D. thesis, Université libre de Bruxelles.

Merin, A., 1999. Information, relevance, and social decisionmaking: some principles and results of Decision-Theoretic Semantics. In: Moss, L., Ginzburg, J., de Rijke, M. (Eds.), Logic, Language and Computation. Vol. 2. CSLI Publications, Stanford, pp. 179-221.

Merin, A., Nikolaeva, I., 2008. Exclamatives as a Universal Speech Act Category: a Case Study in Decision-theoretic Semantics and Typological Implications, ms, University of Konstanz and SOAS London University.

Milner, J. C., 1978. De la syntaxe à l'interprétation: quantités, insultes, exclamations. Seuil, Paris.

Molinier, C., Lévrier, F., 2000. Grammaire des adverbes. Description des formes en -ment. Droz, Geneva. 
Morzycki, M., 2008. Nonrestrictive modifiers in nonparenthetical positions. In: McNally, L., Kennedy, C. (Eds.), Adverbs and adjectives: Syntax, Semantics and Discourse. Oxford University Press, Oxford, pp. 101-122.

Peterson, P., 1997. Facts, Propositions, Events. Kluwer Academic Press, Dordrecht.

Peterson, T., under review. Deconstructing Mirativity: Evidentiality and the Unprepared Mind.

Piñón, C., 2005. Comments on Morzycki and Katz, ms, Hungarian Academy Of Sciences.

URL pinon.sdf-eu .org

Potts, C., 2005. The Logic of Conventional Implicatures. Oxford University Press, Oxford.

Rett, J., Murray, S., 2013. A semantic account of mirative evidentials. In: Snider, T. (Ed.), Proceedings From Semantics and Linguistic Theory XXIII. CLC Publications, pp. 453-472.

Richard, M., 2004. Contextualism and relativism. Philosophical Studies (119), 215-242.

Roberts, C., 1996. Information structure in discourse: toward an integrated formal theory of pragmatics. In: Yoon, J.-H., Kathol, A. (Eds.), OSUWPL Volume 49: Papers in Semantics. The Ohio State University, Department of Linguistics, pp. 91-136.

Sedivy, J., 2003. Pragmatic versus form-based accounts of referential contrast: Evidence for effects of informativity expectations. Journal of Psycholinguistics Research 32/1, 3-24.

Sedivy, J., Tanenhaus, M., Chambers, C., Carlson, G., 1999. Achieving incremental semantic interpretation through contextual representation. Cognition 71, $109-147$.

Shaer, B., 2000. Syntactic position and the readings of 'manner' adverbs. ZAS Papers in Linguistics 17, 265-286.

Stephenson, T., 2007. Towards a Theory of Subjective Meaning. Ph.D. thesis, MIT.

Thuilier, J., 2012. Contraintes préférentielles et ordre des mots en français. Ph.D. thesis, Université Paris Diderot.

Umbach, C., 2006. Non-restrictive modification and backgrounding. In: Proceedings of Lola 9. pp. 152-159.

Umbach, C., 2012a. Non-restrictive Modification and Evaluativity, talk presented at the workshop Semantic and Pragmatic Properties of (Non)Restrictivity, Stuttgart, March 19th-20th 2012.

Umbach, C., 2012b. Non-restrictive Modification by Evaluative Predicates, talk presented at the workshop Information, Discourse Structure and Levels of Meaning, Barcelona, October 25th-26th 2012. 
Vincent, N., 1988. Italian. In: Harris, M., Vincent, N. (Eds.), The Romance Languages. Croom Helm, London, pp. 279-285.

Wettstein, H., 1991. Has Semantics Rested on a Mistake? and Other Essays. Stanford University Press, Palo Alto, Ch. Demonstrative Reference and Definite Descriptions.

Wilmet, M., 1980. Antéposition et postposition de l'épithète qualificative en français contemporain. Travaux de linguistique 7, 179-201. 